\title{
Reliability and Validity of Simple Stroke Food Frequency Questionnaire (SS-FFQ) for Nutrition Monitoring in Patients with Acute Ischemic Stroke
}

\author{
Reza Tabrizi ${ }^{1}$ Afshin Borhani-Haghighi ${ }^{2}$ Kamran B. Lankarani ${ }^{1}$ Parisa Keshani ${ }^{3}$ \\ Seyed Taghi Heydari ${ }^{1}$ Pedram Keshavarz ${ }^{4}$ M. Reza Azarpazhooh,5,6,
}

\footnotetext{
${ }^{1}$ Health Policy Research Center, Institute of Health, Shiraz University of Medical Sciences, Shiraz, Iran

${ }^{2}$ Clinical Neurology Research Center, Shiraz University of Medical Sciences, Shiraz, Iran

${ }^{3}$ Department of Community Nutrition, School of Nutrition and food Sciences, Shiraz University of Medical Sciences, Shiraz, Iran

${ }^{4}$ Student Research Committee, Shiraz University of Medical

Sciences, Shiraz, Iran

${ }^{5}$ Department of Neurology, Ghaem Hospital, School of Medicine, Mashhad University of Medical Sciences, Mashhad, Iran
}

\begin{abstract}
Address for correspondence Afshin Borhan-Haghighi, MD, Clinical Neurology Research Center, Shiraz University of Medical Sciences, Research Tower, Khalili Avenue, Shiraz 71936-35899, I.R. Iran (e-mail: neuro.ab@gmail.com).

6Department of Clinical Neurological Sciences \& Department of
Epidemiology and Biostatistics, Western University, London,
Ontario, Canada
\end{abstract}

J Neurosci Rural Pract:2021;12:51-59

\begin{abstract}
Keywords

- validity

- reliability

- dietary questionnaire

- Food Frequency

Questionnaire

- ischemic stroke
\end{abstract}

Objectives Standard dietary questionnaires may have some limitations in cases with stroke, particularly in those suffering from language and communication difficulties. The present study aimed to develop a dietary questionnaire appropriate for patients with acute ischemic stroke (AIS).

Materials and Methods Major food groups $(n=19)$ were first identified using the dietary questionnaire of the INTERHEART study. Using the Food Frequency Questionnaire (FFQ), an expert dietitian and a vascular neurologist then selected a total number of 68 corresponding food items from 168 available FFQ items. In the next phase, a panel of expert dietitians $(n=10)$ assessed the face validity and the content validity of these 68 items and approved a total number of 62 items for the final questionnaire, namely, the Simple Stroke FFQ (SS-FFQ). Employing test-retest method, the intraclass correlation (ICC) of the SS-FFQ was subsequently calculated in 30 randomly selected cases affected with AIS. Ultimately, principal component analysis (PCA) was utilized for 153 cases with AIS to assess the construct validity of the questionnaire concerned. The SPSS Statistics software (version 18: SPSS Inc., Chicago, Illinois, United States) as well as descriptive tests including mean and percentage were additionally used to account for the baseline characteristics of the study participants.

Results The results revealed that the reliability of the newly developed form of the SS-FFQ was perfect $(I C C=0.86)$. Dietary conditions were further assessed administering the SS-FFQ on 153 cases of AIS with the mean age of $63.76 \pm 15.93$ years. The PCA results also showed that 15 extracted items of the given questionnaire could explain $73.10 \%$ of total item variance.

Conclusions It was concluded that the SS-FFQ was a valid and reliable questionnaire to assess nutrient intakes among patients with AIS.
DOI https://doi.org/ $10.1055 / \mathrm{s}-0040-1718843$ ISSN 0976-3147. (c) 2020. Association for Helping Neurosurgical Sick People.

This is an open access article published by Thieme under the terms of the Creative Commons Attribution-NonDerivative-NonCommercial-License, permitting copying and reproduction so long as the original work is given appropriate credit. Contents may not be used for commercial purposes, or adapted, remixed, transformed or built upon. (https://creativecommons.org/licenses/by-nc-nd/4.0/)

Thieme Medical and Scientific Publishers Pvt. Ltd., A-12, 2nd Floor, Sector 2, Noida-201301 UP, India 


\section{Introduction}

Poor dietary habits have been recognized as the second leading cause of stroke-induced mortality worldwide. ${ }^{1}$ As well, one of the most important challenges in epidemiological studies of nutrition is lack of feasible and valid dietary assessment tools. ${ }^{2}$ The Food Frequency Questionnaire (FFQ) is commonly used in nutritional epidemiology to examine dietary intakes. ${ }^{3,4}$ Moreover, this questionnaire can determine majority of dietary patterns, particularly in healthy individuals. However, it is a long form (consisting of 168 items) and may have some limitations in patients with stroke, who may also suffer from language and communication difficulties. ${ }^{5-7}$ In this regard, Cade et $\mathrm{al}^{8}$ showed that the selected food items in the FFQ were useful and practical for nutrient intake assessment. As well, several studies had validated the simplified FFQ to use it in dietary assessment in different clinical settings. ${ }^{9-11}$

To the best of authors' knowledge, the validity of the FFQ the simplified version, has not been thus far assessed in stroke patients. Therefore, the present study was designed to validate and develop a new simplified questionnaire for cases with acute ischemic stroke (AIS).

\section{Materials and Methods}

\section{Study Design}

Using the dietary questionnaire of the INTERHEART study, major food groups ( $n=19$ ) were initially identified. ${ }^{12}$ These food groups had been so far provided as a generic questionnaire that could be used for participants from 52 countries to assess food intakes. Then, an expert dietitian (PK) and a vascular neurologist $(\mathrm{ABH})$ selected and confirmed 68 corresponding food items for each food group, from the validated FFQ version for Iranian foods (namely 168 items $)^{4}$ to identify the corresponding items. In the next phase, expert dietitians $(n=10)$ independently assessed face validity and content validity of these 68 selected items. During face validity, most experts recommended clarification and simplicity of the food items. For content validity, nutritionists comparably checked each food item to determine if they had necessity and relevance for the given questionnaire according to two main measures: (1) content validity ratio (CVR) and (2) content validity index (CVI). The necessity of each dietary item was accordingly assessed using CVR based on a three-point rating measure: "(1) not necessary, (2) useful, but not essential, (3) essential." If CVR for each food item was $\geq 62 \%$, this item could be kept in the questionnaire. ${ }^{13}$ Similar to Waltz and Bausell, ${ }^{14}$ a fourpoint rating measure CVI was further employed to assess the relevance of each item. Therefore, the items with CVI scores $\geq 75 \%$ were selected. Using CVI and CVR scoring cutoffs, 62 items were finally approved, and a new simplified dietary questionnaire was developed to assess cases with stroke, namely, Simple Stroke FFQ (SS-FFQ).

In the next step, 30 cases affected with AIS with the mean age of $61.33 \pm 15.04$ years were randomly selected. Test-retest method was also performed to calculate the intraclass correlation (ICC) of the SS-FFQ in these cases. The cases were accordingly interviewed by a trained nutritionist, and subsequently they completed the SS-FFQ based on a 2-week interval. The ICC score agreement was categorized into scores>0.81: perfect; 0.61 to 0.80 : substantial, 0.41 to 60 moderate, 0.21 to 0.40 : fair; and 0 to 0.20 : slight. ${ }^{15}$

Finally, to assess construct validity, principal component analysis (PCA) was used. For this purpose, 153 cases with AIS were consecutively interviewed by a trained nutritionist. To extract the principal components, varimax rotation technique was employed and components with an eigenvalue $>1.0$ were identified. Prior to applying the PCA, appropriate assumptions including Kaiser-Meyer-Olkin measure and Bartlett's test were first considered. Accordingly, the items were selected if they were loaded above $0.3 .{ }^{16}$ Moreover, the findings revealed that the factor loading of all the selected items in the SS-FFQ was above 0.3. The patients included in this study were those admitted between October 1, 2018, and September 20, 2019, to Namazi Hospital, as a tertiary referral center in the city of Shiraz, Southern Iran. They were also asked about the frequency (daily, weekly, monthly, or yearly) and the amount (an open-ended question for each item) of all food intakes within the last year before the stroke. Using a dietary assessment standard tool, the total quantitative amount (namely serving size) of each item was comparably calculated. In cases with any language and communication problems (e.g., aphasia and neglect), the proxy of family member responded to the dietary questionnaire based on a self-report of consumption of food items. A comprehensive framework was thus summarized for developing a valid and reliable questionnaire in $\boldsymbol{- F i g . ~} \mathbf{1}$.

Table 1 Characteristics of study population

\begin{tabular}{|l|l|l|}
\hline Variables & Number (\%) & $\mathrm{M} \pm \mathrm{SD}$ \\
\hline Age (year) & & $63.73 \pm 15.93$ \\
\hline BMI (kg/m²) & & $26.62 \pm 4.70$ \\
\hline Duration of education (year) & & $6.07 \pm 5.68$ \\
\hline Gender & & \\
\hline Male & $96(62.7)$ & \\
\hline Female & $57(37.3)$ & \\
\hline $\begin{array}{l}\text { Physical activity (METs } \\
\text { minute/week) }\end{array}$ & & \\
\hline$<600$ METs & $98(64.0)$ & \\
\hline $600-1500$ METs & $45(29.4)$ & \\
\hline $1500-3000$ METs & $7(4.6)$ & \\
\hline$>3000$ METs & $3(2.0)$ & \\
\hline Marital status & & \\
\hline Married & $111(72.5)$ & \\
\hline Single/widowed/divorced & $42(27.5)$ & \\
\hline
\end{tabular}

Abbreviations: BMI, body mass index; MET, metabolic equivalent task; $\mathrm{SD}$, standard deviation. 


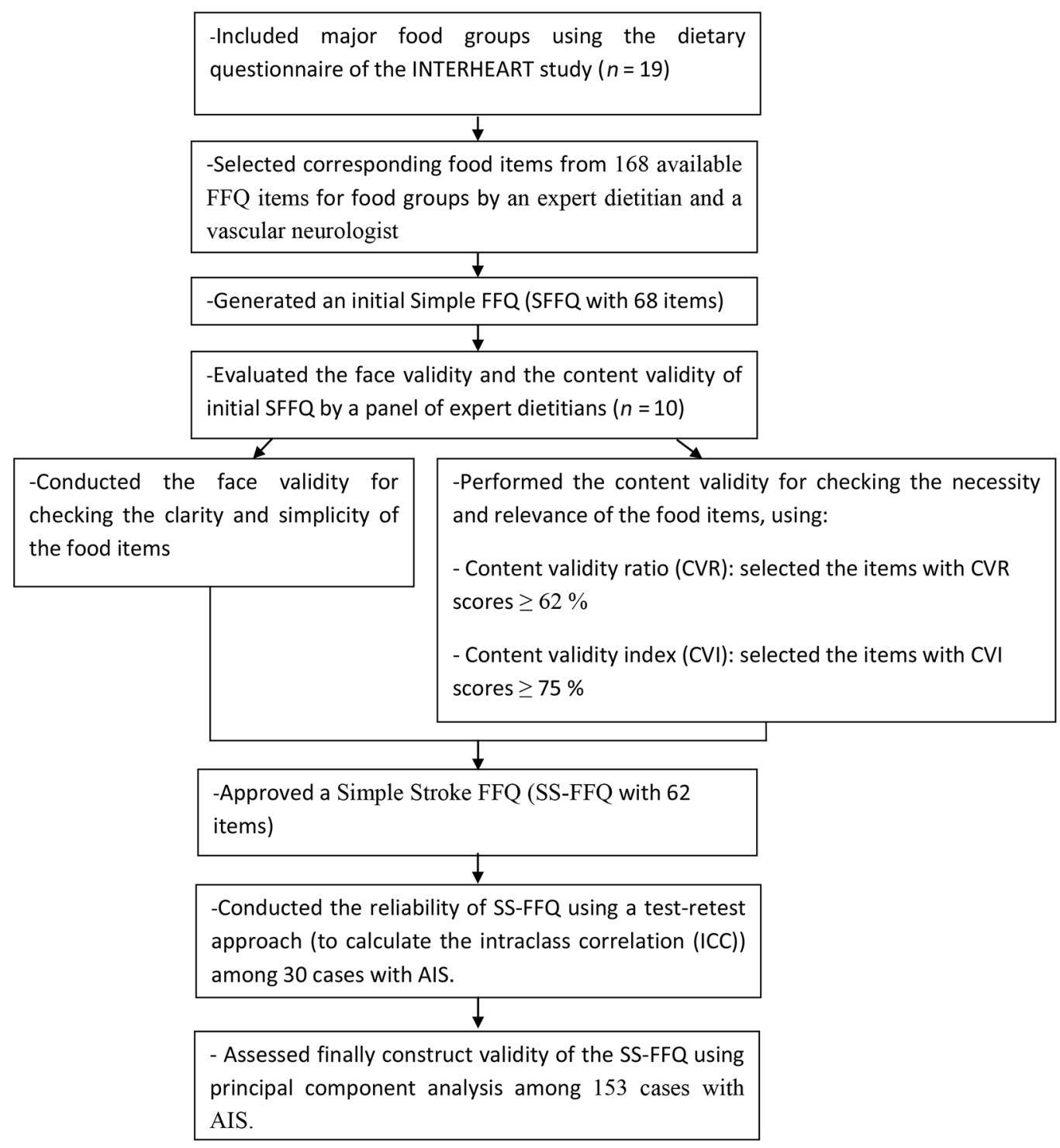

Fig. 1 A framework for developing valid and reliable SS-FFQ.

\section{Statistical Analysis}

All analyses were conducted using the SPSS Statistics software (version 18; SPSS Inc., Chicago, Illinois, United States). All the continuous variables were accordingly reported as mean \pm standard deviation, and the categorical ones were presented as number (percentages). Moreover, descriptive tests including mean and percentage were used to explain the baseline characteristics of the study participants.

\section{Results}

The baseline characteristics of the study participants are summarized in - Table 1. The population study included 153 individuals (96 males and 57 females, mean age: $63.73 \pm 15.93$ years). The participants' body mass index and duration of education were also respectively $26.62 \pm 4.70$ and $6.07 \pm 5.68$ years.
It should be noted that factor analysis using the PCA is one of useful methods for testing construct validity and extracting factors of a new instrument. After checking the required assumptions for the PCA, 15 components were identified that could generally explain $73.10 \%$ of total item variance (-Table 2 ). Moreover, the items were selected if they were loaded above 0.30 , so all of them were included in the SS-FFQ concerned.

Most of the food items were listed in F1 and F2 components. Among the 14 food items included in F1 component, citrus fruits (orange, tangerine, sweet lemon, etc.), kiwifruit as well as watermelon, honeydew, and Persian melon showed the highest values (0.77). These items were then followed by peach, nectarine, apricot, plum (0.74), apple (0.73), and dried fruits (raisin, dried berries, dried fig, date, etc.) and all kinds of fresh leafy green vegetables such as spinach, parsley, and basil (0.72). Moreover, 17 food items were included in F2 component, such as 
Table 2 Factor loadings of each item after factor rotation using varimax rotation technique among AIS patients

\begin{tabular}{|c|c|c|c|c|c|c|c|c|c|c|c|c|c|c|c|}
\hline & F1 & $\mathrm{F} 2$ & F3 & F4 & F5 & F6 & F7 & F8 & F9 & F10 & F11 & F12 & F13 & F14 & F15 \\
\hline $\begin{array}{l}\text { Lentils, dried beans, } \\
\text { dried peas, split } \\
\text { peas, and soybeans }\end{array}$ & 0.39 & & & & & & & & & & & & & & \\
\hline $\begin{array}{l}\text { Salted almond, } \\
\text { walnut, hazelnut, } \\
\text { peanut, pistachio, } \\
\text { and sunflower seeds, } \\
\text { or any other nuts/ } \\
\text { seeds }\end{array}$ & 0.50 & & & & & & & & & & & & & & \\
\hline Apple & 0.73 & & & & & & & & & & & & & & \\
\hline Banana & 0.68 & & & & & & & & & & & & & & \\
\hline $\begin{array}{l}\text { Citrus fruits (orange, } \\
\text { tangerine, sweet } \\
\text { lemons, etc.), and } \\
\text { kiwifruit }\end{array}$ & 0.77 & & & & & & & & & & & & & & \\
\hline Cherries and berries & 0.65 & & & & & & & & & & & & & & \\
\hline $\begin{array}{l}\text { Watermelon, } \\
\text { honeydew, and } \\
\text { Persian melon }\end{array}$ & 0.77 & & & & & & & & & & & & & & \\
\hline $\begin{array}{l}\text { Peach, nectarine, } \\
\text { apricot, and plum }\end{array}$ & 0.74 & & & & & & & & & & & & & & \\
\hline $\begin{array}{l}\text { Dried fruits (raisin, } \\
\text { dried berries, dried } \\
\text { fig, date, etc.) }\end{array}$ & 0.72 & & & & & & & & & & & & & & \\
\hline $\begin{array}{l}\text { All kinds of fresh leafy } \\
\text { green vegetables } \\
\text { such as spinach, } \\
\text { parsley, basil, etc. }\end{array}$ & 0.72 & & & & & & & & & & & & & & \\
\hline Tomato & 0.69 & & & & & & & & & & & & & & \\
\hline $\begin{array}{l}\text { Zucchini and } \\
\text { eggplant }\end{array}$ & 0.65 & & & & & & & & & & & & & & \\
\hline Carrot & 0.66 & & & & & & & & & & & & & & \\
\hline $\begin{array}{l}\text { Tea, sugar-free } \\
\text { coffee or Nescafe }\end{array}$ & 0.65 & & & & & & & & & & & & & & \\
\hline $\begin{array}{l}\text { Beef, lamb, veal } \\
\text { (grilled, minced, and } \\
\text { fried) }\end{array}$ & & 0.37 & & & & & & & & & & & & & \\
\hline $\begin{array}{l}\text { Organ meats (liver, } \\
\text { lung, kidney, and } \\
\text { heart) }\end{array}$ & & 0.35 & & & & & & & & & & & & & \\
\hline Brain & & 0.50 & & & & & & & & & & & & & \\
\hline $\begin{array}{l}\text { Chicken egg and } \\
\text { other kinds of } \\
\text { bird eggs }\end{array}$ & & 0.42 & & & & & & & & & & & & & \\
\hline $\begin{array}{l}\text { Traditional bread } \\
\text { such as lavash, } \\
\text { barbari, and sangak, } \\
\text { and toast and } \\
\text { baguette (made of } \\
\text { refined grains) }\end{array}$ & & 0.53 & & & & & & & & & & & & & \\
\hline White rice & & 0.50 & & & & & & & & & & & & & \\
\hline $\begin{array}{l}\text { Pizza cheese or other } \\
\text { types of cheese }\end{array}$ & & 0.37 & & & & & & & & & & & & & \\
\hline Cream and kaymak & & 0.54 & & & & & & & & & & & & & \\
\hline
\end{tabular}


Reliability and Validity of Simple Stroke Food Frequency Questionnaire Tabrizi et al. 55

Table 2 (Continued)

\begin{tabular}{|c|c|c|c|c|c|c|c|c|c|c|c|c|c|c|c|}
\hline & $\mathrm{F} 1$ & F2 & F3 & $\mathrm{F} 4$ & F5 & F6 & F7 & F8 & F9 & F10 & F11 & F12 & F13 & F14 & F15 \\
\hline $\begin{array}{l}\text { Deep-fried foods } \\
\text { (such as cutlet, } \\
\text { fried eggplant, fried } \\
\text { bread, French fries, } \\
\text { etc.) }\end{array}$ & & 0.42 & & & & & & & & & & & & & \\
\hline $\begin{array}{l}\text { Butter (animal origin } \\
\text { or margarine) }\end{array}$ & & 0.35 & & & & & & & & & & & & & \\
\hline Full-fat yogurt & & 0.36 & & & & & & & & & & & & & \\
\hline $\begin{array}{l}\text { Cakes, chocolates, } \\
\text { biscuits, traditional } \\
\text { sweets, and pastry } \\
\text { (sweet snacks) }\end{array}$ & & 0.34 & & & & & & & & & & & & & \\
\hline $\begin{array}{l}\text { Sugar cube, sugar, } \\
\text { candy, and tradi- } \\
\text { tional candies }\end{array}$ & & 0.40 & & & & & & & & & & & & & \\
\hline $\begin{array}{l}\text { Soft drink, soda, and } \\
\text { nonalcoholic beer }\end{array}$ & & 0.45 & & & & & & & & & & & & & \\
\hline Potato (boiled) & & 0.42 & & & & & & & & & & & & & \\
\hline $\begin{array}{l}\text { Starchy vegetables } \\
\text { such as broad beans, } \\
\text { green peas, pumpkin, } \\
\text { corns }\end{array}$ & & 0.44 & & & & & & & & & & & & & \\
\hline $\begin{array}{l}\text { Pasta, vermicelli, or } \\
\text { noodles }\end{array}$ & & 0.49 & & & & & & & & & & & & & \\
\hline Fish & & & 0.46 & & & & & & & & & & & & \\
\hline Shrimp & & & 0.43 & & & & & & & & & & & & \\
\hline Low-fat yogurt & & & 0.48 & & & & & & & & & & & & \\
\hline Low-fat milk & & & 0.51 & & & & & & & & & & & & \\
\hline White cheese & & & & 0.45 & & & & & & & & & & & \\
\hline $\begin{array}{l}\text { Other raw nonstarchy } \\
\text { vegetables (lettuce, } \\
\text { cauliflower, cabbage, } \\
\text { celery, mush- } \\
\text { room, etc.) }\end{array}$ & & & & 0.32 & & & & & & & & & & & \\
\hline Cucumber & & & & 0.62 & & & & & & & & & & & \\
\hline $\begin{array}{l}\text { All kinds of } \\
\text { cooked vegetables } \\
\text { (nonstarchy cooked } \\
\text { vegetables) }\end{array}$ & & & & 0.62 & & & & & & & & & & & \\
\hline $\begin{array}{l}\text { Salt-free almond, } \\
\text { walnut, hazelnut, } \\
\text { peanut, pistachio, } \\
\text { and sunflower seeds, } \\
\text { or any other nuts/ } \\
\text { seeds }\end{array}$ & & & & 0.58 & & & & & & & & & & & \\
\hline $\begin{array}{l}\text { Face meat and } \\
\text { tongue }\end{array}$ & & & & & 0.36 & & & & & & & & & & \\
\hline Rumen & & & & & 0.50 & & & & & & & & & & \\
\hline Ice cream & & & & & 0.40 & & & & & & & & & & \\
\hline $\begin{array}{l}\text { Cheese puffs, chips, } \\
\text { pretz, etc. (salty } \\
\text { snacks) }\end{array}$ & & & & & 0.56 & & & & & & & & & & \\
\hline $\begin{array}{l}\text { Jam, honey, date } \\
\text { syrup, and grape } \\
\text { syrup }\end{array}$ & & & & & 0.63 & & & & & & & & & & \\
\hline
\end{tabular}


Table 2 (Continued)

\begin{tabular}{|c|c|c|c|c|c|c|c|c|c|c|c|c|c|c|c|}
\hline & F1 & $\mathrm{F} 2$ & F3 & $\mathrm{F} 4$ & F5 & F6 & F7 & F8 & F9 & F10 & F11 & F12 & F13 & F14 & F15 \\
\hline $\begin{array}{l}\text { Kinds of canned } \\
\text { foods (salty food) }\end{array}$ & & & & & & 0.50 & & & & & & & & & \\
\hline Herbal tea & & & & & & & 0.60 & & & & & & & & \\
\hline $\begin{array}{l}\text { Tea, coffee, or } \\
\text { Nescafe (bitter or } \\
\text { sweet) }\end{array}$ & & & & & & & 0.60 & & & & & & & & \\
\hline $\begin{array}{l}\text { Flavored milk or } \\
\text { yogurt }\end{array}$ & & & & & & & & 0.38 & & & & & & & \\
\hline Potato $^{2}$ & & & & & & & & 0.30 & & & & & & & \\
\hline $\begin{array}{l}\text { Beef, lamb, and veal } \\
\text { (stewed) }\end{array}$ & & & & & & & & & 0.40 & & & & & & \\
\hline $\begin{array}{l}\text { Chicken and turkey } \\
\text { (or other poultry) }\end{array}$ & & & & & & & & & 0.41 & & & & & & \\
\hline Sausages or ham & & & & & & & & & & 0.33 & & & & & \\
\hline Mayonnaise & & & & & & & & & & 0.31 & & & & & \\
\hline Full-fat milk & & & & & & & & & & & 0.54 & & & & \\
\hline Fruit juices & & & & & & & & & & & & 0.34 & & & \\
\hline $\begin{array}{l}\text { Wheat, barley, oats } \\
\text { (whole-grain) }\end{array}$ & & & & & & & & & & & & & 0.43 & & \\
\hline Whole-grain bread & & & & & & & & & & & & & 0.48 & & \\
\hline $\begin{array}{l}\text { Fruit juice } \\
\text { concentrates }\end{array}$ & & & & & & & & & & & & & & 0.42 & \\
\hline Whey (kishk) & & & & & & & & & & & & & & & 0.43 \\
\hline Yogurt drink & & & & & & & & & & & & & & & 0.50 \\
\hline
\end{tabular}

Abbreviation: AIS, acute ischemic stroke.

Note: Values indicate items with factor loadings $\geq 0.30$.

cream and kaymak, which obtained the highest values by 0.54 . Then, traditional bread such as lavash, barbari, sangak, and toast and baguette (made of refined grains) attained higher values (0.53), followed by white rice, which had the same value as 0.50 . With respect to F4 and F5 components, they experienced the next higher number of food items (namely, each category consisting of five food items). Both cucumber and all kinds of cooked vegetables (nonstarchy cooked vegetables) showed the highest values $(0.62)$ in F4 component, while the food item group of jam, honey, date syrup, and grape syrup had the higher amount in F5 component (0.63). As well, F3 component encompassed four food items in which low-fat milk (0.51) and low-fat yogurt (0.48) demonstrated the highest values.

Additionally, F6 to F15 components showed utmost two food items. Briefly, F6-F10, F13, and F15 components revealed two food items in each component, while F11, F12, and F14 components were comprised of one food item. The highest values in F6 to F10 components were respectively associated with kinds of canned foods (i.e., salty food) ( 0.50$)$, herbal tea, tea, coffee or Nescafe (sweet) (0.60), flavored milk or yogurt (0.38), chicken and turkey (or other poultry) (0.41), and sausages or ham (0.33). Whole-grain bread (0.48) and yogurt drink (0.50) were, respectively, the food items with the highest values in F13 and F15 components. Besides, full-fat milk (0.54), fruit juices (0.34), and fruit juice concentrates (0.42) were respectively the only food items in F11, F12, and F15 components.

- Table 3 shows the classification of final SS-FFQ. The findings of test-retest method, using the ICC, also established that the \pm reliability of the given questionnaire was 0.86 at twotime intervals. This score demonstrated that the reliability was perfect for the SS-FFQ concerned.

\section{Discussion}

Stroke is known as one of the leading causes of disability and mortality in developing and developed countries alike. ${ }^{17,18}$ Throughout the future decades, stroke, which absorbs enormous health services and contributes to a major economic burden due to population aging, will also become a huge burden for the health care system. ${ }^{19}$ This condition, however, has a significant effect not only on governments but also on patients and families. Hence, it is crucial to formulate preventive approaches to reduce the risk of stroke. In this respect, diet is one of the most significant lifestyle-related variables involved in stroke prevention. Recently, comprehensive epidemiological research studies have put much emphasis on nutrient associations, food classes, and stroke. Compared with nutrients and dietary habits, food groups are more widely accepted and reasonable to the 
Table 3 Classification of final nutrient profiles in SS-FFQ

\begin{tabular}{|c|c|}
\hline Food groups & Items \\
\hline Meat/poultry & $\begin{array}{l}\text { Beef, lamb, veal (stewed, grilled, and minced), chicken, turkey (or other poultry), organ meats (liver, } \\
\text { lung, kidney, heart, brain, face meat and tongue, rumen, foot), and sausages or ham }\end{array}$ \\
\hline Sea food & Types of fish and shrimp \\
\hline Eggs & Chicken egg and kinds of bird eggs \\
\hline Whole grains & Whole-meal bread including wheat, barley, and oats \\
\hline Refined grains & $\begin{array}{l}\text { Kinds of white beards (traditional bread such as lavash, barbari, and sangak, and toast, baguette } \\
\text { (made of refined grains), white rice, pasta, vermicelli, or noodles }\end{array}$ \\
\hline Dairy products & $\begin{array}{l}\text { Milk (full- or low-fat), yogurt (full- or low-fat), yogurt drink, whey (kishk), ice cream, flavored milk or } \\
\text { yogurt, white cheese, pizza cheese or other type of cheese, cream, and kaymak }\end{array}$ \\
\hline Fats and deep-fried foods & $\begin{array}{l}\text { Fried potato, cutlet, fried eggplant, fried bread, deep-fried foods, vegetable butter, animal butter, } \\
\text { ghee, and mayonnaise }\end{array}$ \\
\hline Salty foods & Kinds of canned foods \\
\hline Salty snacks & Cheese puffs, chips, pretz, etc. \\
\hline Pickled vegetables & Pickled cucumber, salted cauliflower, and other kinds of pickles in salt-water or vinegar \\
\hline Sweet snacks & Cakes, chocolates, biscuits, traditional sweets (such as gaz and sohan), and pastry \\
\hline Sugar/sweeteners & $\begin{array}{l}\text { Sugar cube, sugar, candy, and traditional candies (such as shekarpanir and poolaki), jam, honey, date } \\
\text { syrup, grape syrup, industrial fruit juices, and soft drinks, non-alcoholic beer }\end{array}$ \\
\hline Legumes & Lentils, dried beans, dried peas, split peas, and soybeans \\
\hline Nuts/seeds & $\begin{array}{l}\text { Salt-free/salted almond, walnut, hazelnut, peanut, pistachio, and sunflower seeds, or any other nuts/ } \\
\text { seeds }\end{array}$ \\
\hline Fruit/natural juices & $\begin{array}{l}\text { Apple, banana, citrus fruits (orange, tangerine, sweet lemon, etc.), kiwifruit, cherries, berries, water- } \\
\text { melon, honeydew, Persian melon, peach, nectarine, apricot, plum, fruit juices, and dried fruits (raisin, } \\
\text { dried berries, dried fig, date, etc.) }\end{array}$ \\
\hline Leafy greens & All kinds of fresh leafy green vegetables such as spinach, parsley, and basil \\
\hline Non-starchy raw vegetables & $\begin{array}{l}\text { Tomato, zucchini, eggplant, carrot, other raw vegetables (lettuce, cauliflower, cabbage, celery, mush- } \\
\text { room, etc.), and cucumber }\end{array}$ \\
\hline Nonstarchy cooked vegetables & all kinds of cooked vegetables \\
\hline Starchy vegetables & Broad beans, green peas, pumpkin, corns, and potato (fried and boiled) \\
\hline Hot drinks & Tea, coffee, Nescafe (bitter or sweet), and herbal tea \\
\hline
\end{tabular}

Abbreviation: SS-FFQ, simple stroke food frequency questionnaire.

public. Therefore, the present study considered food groups and developed a useful questionnaire to help researchers and clinicians predict nutrient intakes in patients with AIS. The study results revealed that the newly developed SS-FFQ contained nutrient components with acceptable validity and reliability for patients affected with AIS. This SS-FFQ may be also useful for future epidemiological studies to evaluate all nutrient intakes among stroke patients.

Of note, content validity is one of the critical first steps of validation in designing a simplified questionnaire. ${ }^{20}$ In the present study, content validity and construct validity were thus conducted to design an appropriate instrument to assess food frequency among AIS patients.

In this line, previous studies had reported numerous advantages to being confident of the content validity of a questionnaire such as improving the quality and increasing the reliability of the new instrument. ${ }^{21,22}$ Therefore, the quality of the research tool recruited in the present study was boosted using quantification in content validation.

The PCA is similarly one of the complex and useful approaches and the most subjective one to extract components. Therefore, 15 components were retained through construct validity using the PCA based on the eigenvalues greater than 1.0 for the given questionnaire. In this respect, Costello and Osborne ${ }^{23}$ had further reported that selecting components based on eigenvalues $>1.0$ was one of least accurate approaches. In line with previous studies by De Stefani et al and Juhn et al, ${ }^{24,25}$ eigenvalues $>1.0$ were utilized for data analysis to extract the components.

Besides, Kartal and Özsoy ${ }^{26}$ had demonstrated that explaining higher than $30 \%$ of total variance could be sufficient. Thus, the results of the present study had further revealed that 15 components could explain the significance of the total observed variance. According to the construct validity findings, the SS-FFQ concerned may be practical to assess food frequency in patients with AIS.

Pervious evidence had further revealed that the ICC value of 0.4 or above was as an adequate value for stability of a new instrument. ${ }^{26}$ The results of test-retest method using the ICC in the present study were 0.86 and it meant that higher reliability might be because of short-term ( 2 weeks) period in checking this quality. Some earlier reports had similarly 
shown that a period with a 2-week interval to evaluate reliability was reasonable. ${ }^{11,27,28}$ However, the reliability results in the present study were perfect.

There were some limitations in measuring the reliability and the validity of the SS-FFQ in this study. At first, reliability might have been overestimated due to the short interval between two periods, whereas this interval might be considered sufficient. Second, the SS-FFQ was not accompanied by other dietary assessment methods as gold standards including a 24-hour diet recall or food records, because completing these dietary assessments was difficult for patients with AIS.

\section{Conclusion}

In this study, a specific SS-FFQ with high accurate nutrient profiles was designed that may be used for investigating associations between dietary intakes and risk of AIS in future studies. The validated questionnaire in this study also offered a cost-effective tool for collecting information concerning dietary intakes. However, the use of the questionnaire concerned in other setting with a different demographic characteristic will need additional validation and development efforts.

\section{Authors' Contributions}

Study concept and design were performed by RT, K.B.-L, and A.B.-H. Acquisition of data analysis, statistical analysis interpretation of data, and drafting of the manuscript were done by R.T., S.T.H, and P.K.; while gathering data R.T. and P.K. did critical revision of the manuscript for important intellectual content. Administrative, technical, and material support were done by R.T., M.R.A, A.B.-H., and finally study supervision was performed by M.R.A., P.K., and A.B.-H.

\section{Ethical Approval}

The study protocol was approved by the Ethics Committee of Shiraz University of Medical Sciences (IR.SUMS. REC.1397.536), Shiraz, Iran. An informed written consent was also obtained from each participant (or the next of kin) prior to any interview.

\section{Conflict of Interest}

None declared.

\section{Acknowledgments}

The authors would like to extend their gratitude to patients, family members, volunteers, and colleagues in Namazi Hospital for their collaboration in this study. This article was derived from a PhD thesis, financially supported by the Vice Chancellor's Office for Research and Technology at Shiraz University of Medical Sciences, Shiraz, Iran (Grant \#1396-01-104-15996).

\section{References}

1 Avan A, Digaleh H, Di Napoli M, et al. Socioeconomic status and stroke incidence, prevalence, mortality, and worldwide burden: an ecological analysis from the Global Burden of Disease Study 2017. BMC Med 2019;17(1):191
2 Pisa PT, Landais E, Margetts B, et al. Inventory on the dietary assessment tools available and needed in Africa: a prerequisite for setting up a common methodological research infrastructure for nutritional surveillance, research, and prevention of diet-related non-communicable diseases. Crit Rev Food Sci Nutr 2018;58(1):37-61

3 Koole JL, Bours MJL, Breedveld-Peters JJ, et al. Evaluating the validity of a food frequency questionnaire in comparison with a 7-day dietary record for measuring dietary intake in a population of survivors of colorectal cancer. J Acad Nutr Diet 2020;120(2):245-257

4 Mirmiran P, Esfahani FH, Mehrabi Y, Hedayati M, Azizi F. Reliability and relative validity of an FFQ for nutrients in the Tehran lipid and glucose study. Public Health Nutr 2010;13(5):654-662

5 Sinanović O, Mrkonjić Z, Zukić S, Vidović M, Imamović K. Post-stroke language disorders. Acta Clin Croat 2011;50(1):79-94

6 Mousavi SM, Milajerdi A, Pouraram H, et al. Adherence to Alternative Healthy Eating Index (AHEI-2010) is not associated with risk of stroke in Iranian adults: a case-control study. Int J Vitam Nutr Res 2019;1:1-8

7 Dearborn JL, Khera T, Peterson M, Shahab Z, Kernan WN. Diet quality in patients with stroke. Stroke Vasc Neurol 2019;4(3):154-157

8 Cade J, Thompson R, Burley V, Warm D. Development, validation and utilisation of food-frequency questionnaires - a review. Public Health Nutr 2002;5(4):567-587

9 Bredin C, Naimimohasses S, Norris S, et al. Development and relative validation of a short food frequency questionnaire for assessing dietary intakes of non-alcoholic fatty liver disease patients. Eur J Nutr 2020;59(2):571-580

10 Kent K, Charlton KE. Development, validation and reproducibility of a food frequency questionnaire to measure flavonoid intake in older Australian adults. Nutr Diet 2018;75(1):106-116

11 Mohammadifard N, Sajjadi F, Maghroun M, Alikhasi H, Nilforoushzadeh F, Sarrafzadegan N. Validation of a simplified food frequency questionnaire for the assessment of dietary habits in Iranian adults: Isfahan Healthy Heart Program, Iran. ARYA Atheroscler 2015;11(2):139-146

12 Iqbal $\mathrm{R}$, Anand $\mathrm{S}$, Ounpuu $\mathrm{S}$, et al; INTERHEART Study Investigators. Dietary patterns and the risk of acute myocardial infarction in 52 countries: results of the INTERHEART study. Circulation 2008;118(19):1929-1937

13 Lawshe $\mathrm{CH}$. A quantitative approach to content validity 1 . Person Psychol 1975;28(4):563-575

14 Waltz CF, Bausell BR, Nursing Research: Design Statistics and Computer Analysis. Philadelphia: F.A. Davis Co. 1981

15 Ghazanfari Z, Niknami S, Ghofranipour F, Hajizadeh E, Montazeri A. Development and psychometric properties of a belief-based Physical Activity Questionnaire for Diabetic Patients (PAQ-DP). BMC Med Res Methodol 2010;10(1):104

16 Izquierdo I, Olea J, Abad FJ. Exploratory factor analysis in validation studies: uses and recommendations. Psicothema 2014;26(3):395-400

17 Yang G, Wang Y, Zeng Y, et al. Rapid health transition in China, 1990-2010: findings from the Global Burden of Disease Study 2010. Lancet 2013;381(9882) :1987-2015

18 Borhani-Haghighi A, Safari R, Heydari ST, et al. Hospital mortality associated with stroke in southern Iran. Iran J Med Sci 2013;38(4):314-320

19 Meschia JF, Bushnell C, Boden-Albala B, et al; American Heart Association Stroke Council; Council on Cardiovascular and Stroke Nursing; Council on Clinical Cardiology; Council on Functional Genomics and Translational Biology; Council on Hypertension. Guidelines for the primary prevention of stroke: a statement for healthcare professionals from the American Heart Association/American Stroke Association. Stroke 2014;45(12):3754-3832 
20 Keshani P, Tavousi M, Montazeri A, Farvid M-S, Perceived benefits and barriers of increased dietary fiber consumption in subjects with type 2 diabetes: validation of a questionnaire. Nutr Sci Diet; 2016:15-23

21 Abdollahpour I, Nedjat S, Noroozian M, Majdzadeh R. Performing content validation process in development of questionnaires. Majallah-i Ipidimiyuluzhi-i Iran 2011;6(4): 66-74

22 Zalaket J, Matta J, Hanna-Wakim L. Development, validity, and reproducibility of a semiquantitative food frequency questionnaire for the assessment of antioxidant vitamins intake in Lebanon. Nutrition 2019;58:11-17

23 Costello $\mathrm{AB}$, Osborne J. Best practices in exploratory factor analysis: four recommendations for getting the most from your analysis. Pract Assess Res Eval 2005;10(7):1-9
24 De Stefani E, Boffetta P, Ronco AL, et al. Nutrient patterns and risk of lung cancer: a factor analysis in Uruguayan men. Lung Cancer 2008;61(3):283-291

25 Juhn YJ, Beebe TJ, Finnie DM, et al. Development and initial testing of a new socioeconomic status measure based on housing data. J Urban Health 2011;88(5):933-944

26 Kartal A, Özsoy SA. Validity and reliability study of the Turkish version of Health Belief Model Scale in diabetic patients. Int J Nurs Stud 2007;44(8):1447-1458

27 Fleiss JL, Design and Analysis of Clinical Experiments. Vol 73. New York: John Wiley \& Sons; 2011

28 Wong JE, Parnell WR, Black KE, Skidmore PM. Reliability and relative validity of a food frequency questionnaire to assess food group intakes in New Zealand adolescents. Nutr J 2012;11:65 